\title{
ANALISIS KONSENTRASI CAMPURAN SENYAWA MENGGUNAKAN VB 2008
}

\author{
Harry S.J. Koleangan ${ }^{1)}$ \\ 1) Program Studi Matematika FMIPA Universitas Sam Ratulangi \\ J1. Kampus Unsrat, Manado 95115 \\ e-mail: koleanganharry@yahoo.com
}

\begin{abstract}
ABSTRAK
Telah dibuat sebuah program aplikasi menggunakan VB 2008 yang ditujukan untuk menganalisis suatu larutan yang berisi campuran senyawa etil-benzena, $o$-silena, $m$-silena, dan $p$-silena. Konsentrasi dari masing-masing senyawa ini ditentukan menggunakan metode eliminasi Gauss dalam bentuk program komputer yang ditulis menggunakan bahasa pemrograman Visual Basic 2008. Penggunaan program ini terhadap suatu data sekunder, memberikan hasil konsentrasi (dalam satuan molar) sebagai berikut: etil-benzena $=0,04153, o$-silena $=0,04067, m$-silena $=$ 0,02772 , dan $p$-silena $=0,02522$.
\end{abstract}

Kata kunci: metode Gauss, VB 2008

\section{ANALYSIS OF MIXED CPMPOUND CONCENTRATION USING VB 2008}

\begin{abstract}
A VB 2008-based application program to analyze a solution containing four different compounds, which are ethyl-benzene, $o$-xylene, $m$-xylene, and $p$-xylene, has been built. Concentration of each compound was then determined by using Gauss elimination method in the form of computer program written in Visual Basic 2008 programming language. Application of the program using the secondary data shows that concentrations (in molar) of each compuound are as follows: ethyl-benzene $=0,04153, o$-xylena $=0,04067, m$ - xylena $=0,02772$, and $p$ - xylena $=$ 0,02522 .
\end{abstract}

Keywords: Gauss method, VB 2008

\section{PENDAHULUAN}

Analisis secara simultan terhadap suatu larutan multi-komponen adalah sukar atau bahkan tidak mungkin dilakukan secara konvensional. Untuk dapat menganalisis larutan seperti ini dapat dilakukan dengan menggunakan metode modern seperti spektroskopi.

Metode spektroskopi untuk analisis larutan multi-komponen didasarkan pada hukum Beer. Hukum ini menyatakan bahwa absorbansi dari suatu larutan yang mengandung suatu spesies yang dapat menyerap sinar adalah berbanding lurus dengan konsentrasi spesies tersebut. Untuk larutan yang mengandung campuran spesies yang mampu menyerap sinar, maka absorbansinya adalah sama dengan jumlah absorbansi dari masing-masing-masing spesies yang ada dalam campuran tersebut.
Dengan demikian, untuk menentukan konsentrasi setiap spesies yang ada dalam suatu campuran maka diperlukan sejumlah persamaan linear yang banyaknya sama dengan banyaknya spesies yang hendak ditentukan konsentrasinya.

Penyelesaian persamaan linear simultan membutuhkan ketelitian yang tinggi dan apabila dilakukan secara manual akan membutuhkan waktu yang cukup lama. Dengan sebuah program komputer, maka penyelesaian tersebut dapat dilakukan dengan waktu yang sangat singkat dengan tingkat akurasi yang tinggi. Tujuan penelitian ini adalah membuat suatu program komputer menggunakan bahasa pemrograman Visual Basic 2008 konsentrasi suatu larutan yang mengandung etil-benzena, $o$-silena, $m$-silena, dan $p$-silena. 


\section{METODOLOGI PENELITIAN}

Data

Data penelitian ini merupakan data sekunder yang diambil dari textbook How to
Use Excel in Analytical Chemistry and in General Scientific Data Analysis tulisan Robert de Levie (2004), dengan rincian seperti pada Tabel 1 .

Tabel 1. Data Penelitian

\begin{tabular}{|c|c|c|c|c|c|}
\hline $\begin{array}{c}\text { Angka } \\
\text { gelombang/cm }\end{array}$ & $\begin{array}{c}\text { etil- } \\
\text { benzena }\end{array}$ & $o$-silena & $m$-silena & $p$-silena & $\begin{array}{c}\text { Campuran } \\
\text { yang tidak } \\
\text { diketahui }\end{array}$ \\
\hline 696,3 & 1,6534 & 0,0 & 0,1289 & 0,0641 & 0,07386 \\
741,2 & 0,5524 & 4,7690 & 0,0668 & 0,0645 & 0,22036 \\
768,0 & 0,1544 & 0,0 & 2,8542 & 0,0492 & 0,08676 \\
795,2 & 0,0768 & 0,0 & 0,0968 & 2,8288 & 0,07721 \\
\hline
\end{tabular}

Perhitungan selengkapnya untuk menentukan konsentrasi setiap spesies dalam larutan yang tidak diketahui dilakukan melalui program komputer yang dibuat.

\section{Algoritma Program}

Ada tiga tahapan utama untuk menyelesaikan suatu persamaan linear simultan. Untuk mempermudah pemrograman, setiap tahapan ini dijadikan prosedur pemrograman tersendiri. Ketiga prosedur tersebut adalah: MasukkanData untuk memasukkan data, Eliminasi untuk melakukan eliminasi, dan SubstitusiBalik untuk melakukan substitusi balik.

Proses eliminasi dilakukan menggunakan metode Gauss. Untuk mempermudah penyajian algoritma untuk proses eliminasi, maka algoritmanya dituliskan dalam bentuk flowchart (Gambar 1 dan 2).

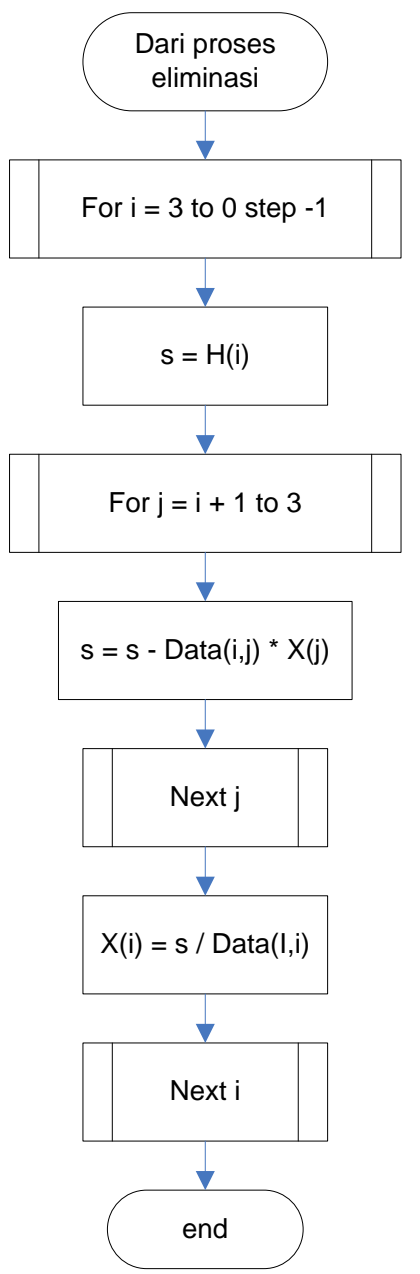

Gambar 2. Flowchart proses substitusi balik. 


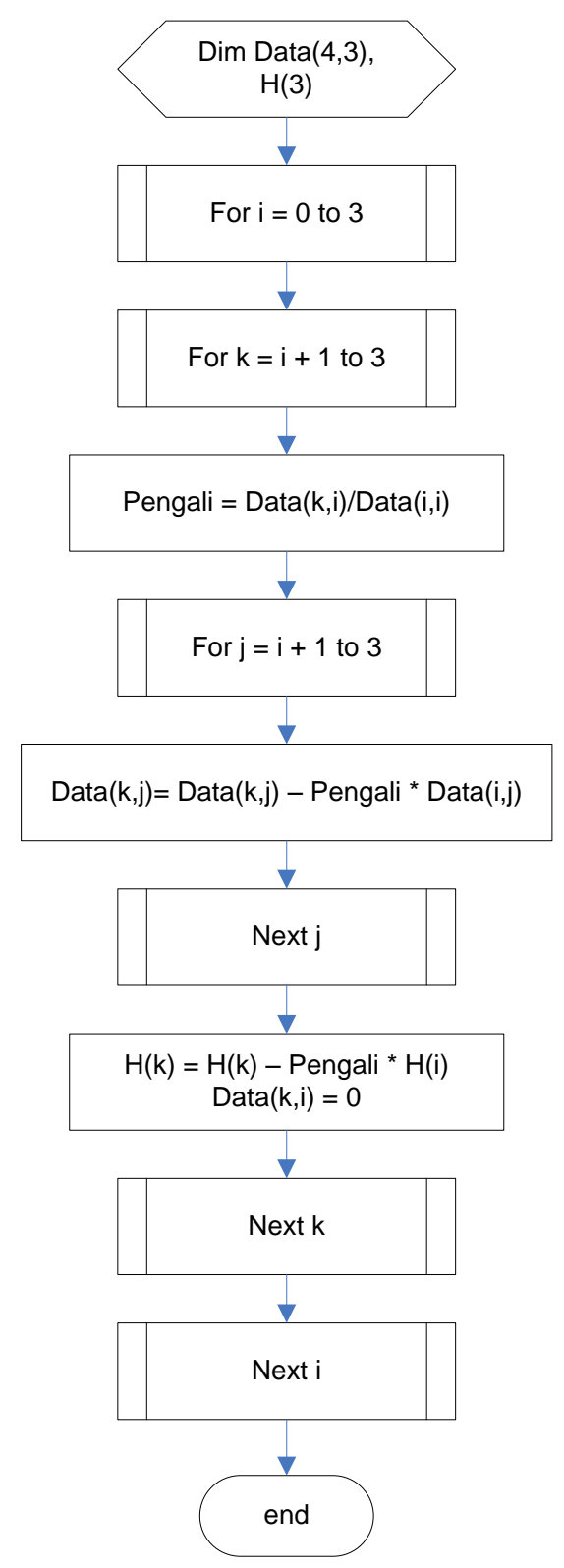

Gambar 1. Flowchart proses eliminasi Gauss.

Selanjutnya, algoritma dari proses substitusi balik dalam bentuk flowchart terlihat pada Gambar 2.

\section{Kode Program}

Kode program selengkapnya dapat dilihat pada lampiran.

\section{HASIL DAN PEMBAHASAN}

Program yang telah dibuat diuji menggunakan data yang ada. Ketika pertama kali dijalankan, program meminta masukkan data. Dengan memasukkan data yang ada maka diperoleh tampilan pada Gambar 3 dan 4.

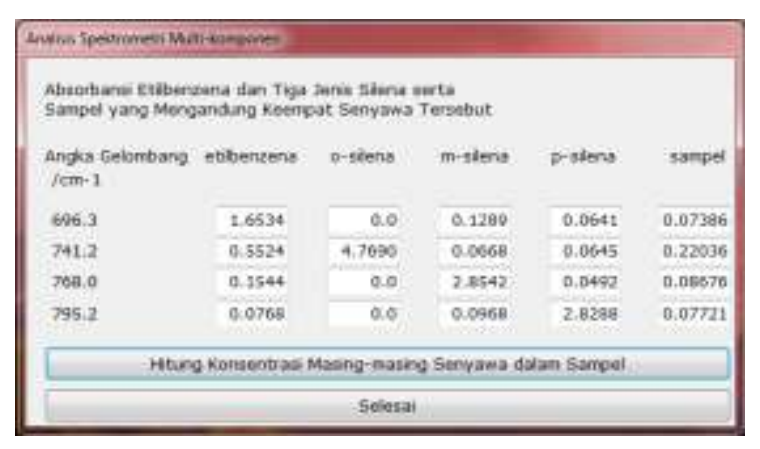

Gambar 3. Tampilan setelah data dimasukkan.

Data yang telah dimasukkan ini selanjutnya diproses untuk menghasilkan persamaan simultan dan dilakukan perhitungan konsentrasi senyawa. Dengan menekan tombol Hitung Konsentrasi Masingmasing Senyawa dalam Sampel, maka program akan menghitung dan menampilkan konsentrasi dari senyawa-senyawa yang ada dalam sampel (Gambar 4).

\begin{tabular}{|lll|}
\hline Kani Pentingan & & \\
\hline Konsentrasi etil benzena dalam sampel & 0.04153 \\
Konsentrasi o-silena dalam sampel & - & 0.04067 \\
Konsentrasi m-silena dalam sampel & $=0.02772$ \\
Konsentrasi p-silena dalam sampel & $=0.02522$ \\
\hline
\end{tabular}

Gambar 4. Tampilan hasil perhitungan.

\section{KESIMPULAN}

Berdasarkan uji program di atas maka dapat disimpulkan bahwa program yang dibuat dapat digunakan untuk menentukan konsentrasi empat senyawa yang ada dalam suatu sampel yang dianalisis secara spektrofotometri, yaitu konsentrasi etil benzena $=0,04153$, konsentrasi $o$-silena $=$ 0,04067 , konsentrasi $m$-silena $=0,02772 \mathrm{M}$, dan konsentrasi $p$-silena $=0,02522 \mathrm{M}$. Keuntungan menggunakan program ini dibandingkan menggunakan metode manual adalah perhitungan dapat dilakukan dengan lebih cepat dengan tingkat ketilitian tinggi dan tidak mengenal lelah. Selain itu, dengan sedikit modifikasi, program ini juga dapat digunakan untuk penentuan konsentrasi senyawa yang jenisnya lebih besar atau lebih 
kecil dari empat yang dianalisis secara spektrofotometri.

\section{DAFTAR PUSTAKA}

Chapra, S. C. and R. P. Canale. 2006. Numerical Methods for Engineers. $5^{\text {th }}$ $E d$. McGraw-Hill, New York, NY 10020.

Conte, S. D. and Carl de Boer. 1980. Elementary Numerical Analysis. An Algorithmic Approach. $3^{\text {rd }} \quad$ Ed. McGraw-Hill, New York.

Dewobroto, W. 2004. Aplikasi Sain dan Teknik dengan Visual Basic 6.0. PT. Elex Media Komputindo. Jakarta.

Kennedy, J. H. 1990. Analytical Chemistry: Principles. Second Edition. Saunders College Publishing.
Munadi, S. 1995. Perhitungan Matriks dengan Quick Basic. Andi Offset. Yogyakarta.

Petroutsos, E., M. Ridgeway. 2008. Mastering Visual 2008. SYBEX Inc., 1151 Marina

Press, W. H., S. A. Teukolsky, W. T. Vetterling, B. P. Flannery. 2007. Numerical Recipes. The Art of Scientific Computing. $3^{\text {rd }}$ Ed., Cambridge University Press.

\section{Lampiran. Kode Program}

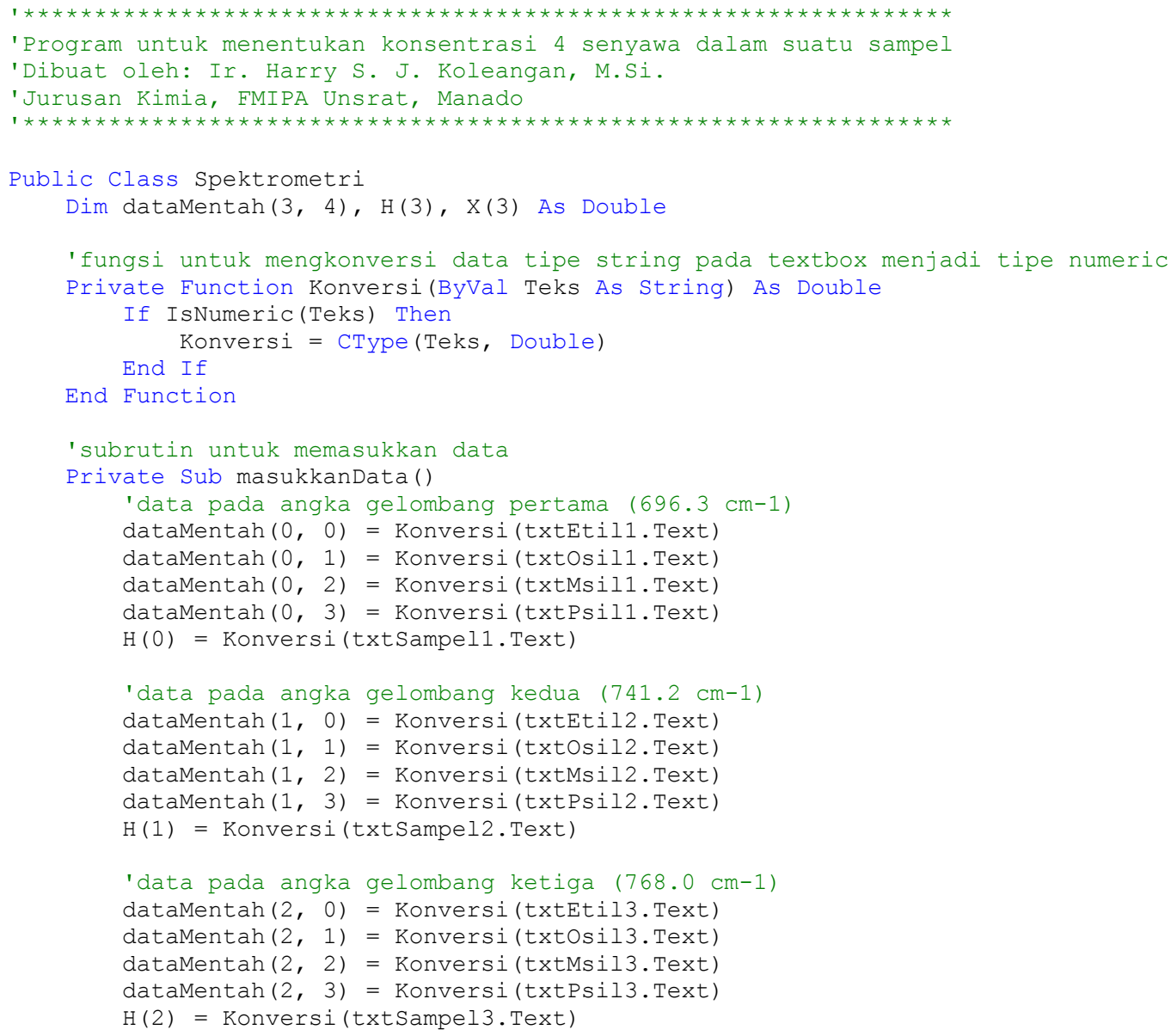




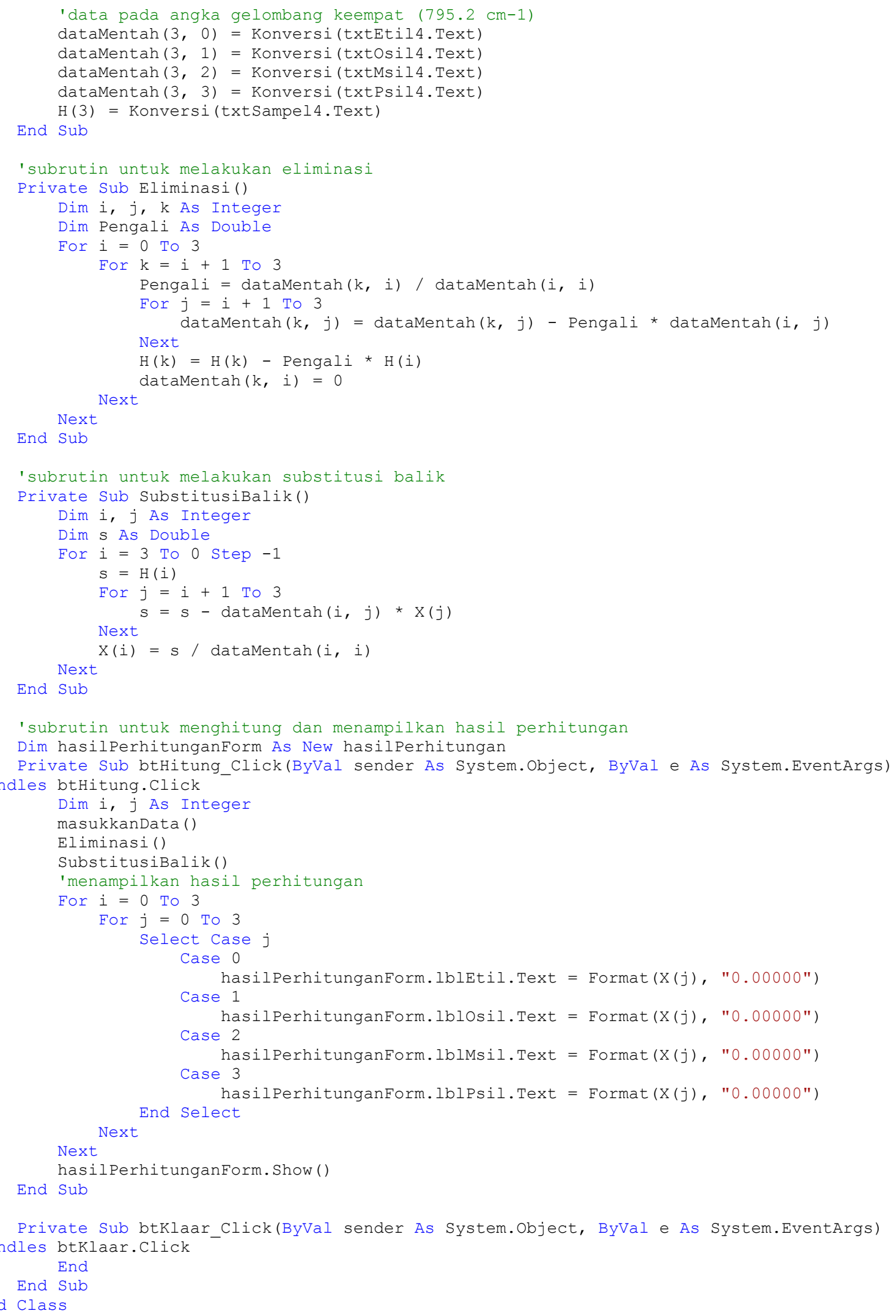

